Revista Mídia e Cotidiano

Artigo Seção Temática

Volume 11, Número 1, abril de 2017

Submetido em: 11/04/2017

Aprovado em: 28/04/2017

\title{
IDENTIDADE, HISTÓRIA E IMAGEM NO PROCESSO DE CRIACÃO DA MARCA DO CONJUNTO PALMEIRAS DURANTE A COPA DO MUNDO FIFA 2014
}

\section{IDENTITY, HISTORY AND IMAGE IN THE PROCESS OF CREATING THE CONJUNTO PALMEIRAS BRAND DURING THE 2014 FIFA WORLD CUP}

\author{
Sílvia Helena BELMINO ${ }^{1}$; Emylianny Brasil DA SILVA²; Luminita-Anda \\ MANDACHE ${ }^{3}$
}

Resumo: A motivação deste estudo foi compreender o uso de estratégias de comunicação e marketing de lugar (KOTLER et al, 2006), pela comunidade periférica do Conjunto Palmeiras, bairro com o pior IDH e apontado nas pesquisas do Estado como o mais violento da cidade de Fortaleza. Neste artigo, apresentamos uma das oficinas com jovens adolescentes sobre a criação de uma identidade visual para complementar a inserção do bairro na Copa do Mundo FIFA 2014. Utilizou-se como método neste trabalho a pesquisaação (Tripp, 2005), com objetivo de refletir sobre a prática das atividades realizadas pelo grupo. Concluiu-se que, ao representar-se por meio da criação de uma marca, o bairro é direto e repetitivo nas fórmulas, buscando ser visto como um local de valores distantes da imagem comumente atrelada ao lugar.

Palavras-chave: Marca; Conjunto Palmeiras; Pesquisa-ação; Consumo.

Abstract: This study aims to understand the use of strategies of communication and marketing of place (KOTLER et al, 2006) by the peripheral community of Conjunto Palmeiras, neighborhood with the worst IDH and pointed in the state surveys as the most violent in the city of Fortaleza. In this article we present one of the workshops with Young people on the creation of a visual identity to complement the insertion of the neighborhood in the 2014 FIFA World Cup. The action-research was used as a method in this work (TRIPP, 2005), with the purpose of reflecting on the practice of the activities carried out by the group. It was concluded that while representing themselves through the creation of a brand, the neighborhood is direct and repetitive in the formulas and seeks to be seen as a place of strong values, distant from the image commonly portrayed of the place.

Keywords: Brand; Conjunto Palmeiras; Action Research; Consumption.

\footnotetext{
$1 \quad$ Professora adjunta IV da UFC, Docente do PPGCOM, doutora e coordenadora do Grupo de Pesquisa de Imagem, Consumo e Experiências Urbanas (Giceu). E-mail: silviahelenabelmino@gmail.com. 2 Mestre em Comunicação e Linguagens pelo Programa de Pós Graduação em Comunicação da Universidade Federal do Ceará. E-mail: emylianny@gmail.com.

Doutoranda em Antropologia Sociocultural na Escola de Antropologia da Universidade do Arizona, com um mestrado em Antropologia Sociocultural da Universidade Católica de Lovaina. Email:luminita.mandache@gmail.com.
} 


\title{
míDiA

Introdução

A retirada de comunidades pobres das suas moradias para realização de grandes empreendimentos imobiliários, megaeventos ou para atender a uma demanda turística, tornou-se uma prática comum nas cidades brasileiras, principalmente naquelas onde prevalecem os interesses econômicos em detrimento dos interesses dos cidadãos. As governanças das grandes cidades do Brasil adotam formatos semelhantes em termos de ocupação do espaço urbano, quais sejam, deixar os pobres em lugares distantes das zonas de maior concentração de renda, gerando cenários de isolamentos geográficos. Um processo de higienização - com registro já nos anos 1930 por ocasião da criação de campos de concentração para aprisionar os flagelados da seca que chegavam à capital cearense, procedentes de cidades do interior do Estado -, é uma prática antiga na administração pública do estado como explica Kênia Rios:

\begin{abstract}
[...] é fundamental entender essas medidas de controle dos retirantes como parte de uma "tradição" de isolamento dos pobres, pois a chegada de migrantes tem sido uma constante na história da cidade sobretudo a partir do final do século XIX. Os Campos de Concentração, entre outros esquemas de isolamentos, fazem parte do diferente uso das secas pelos ricos na tentativa de melhor implementar seus projetos urbanos excludentes na Capital do Ceará no ano de 1932. (RIOS, 2006, pág.42).
\end{abstract}

Fortaleza é uma cidade de contradições, com economia baseada no comércio e no turismo. Possui baixos índices de distribuição de renda ${ }^{4}$ ao mesmo tempo em que é o $9^{\circ}$ maior PIB do país ${ }^{5}$. Eleita em 2010 para ser uma das cidades-sede da Copa das Confederações, realizada em 2013 e da Copa do Mundo FIFA 2014, a capital cearense viu-se envolvida em projetos de adequação às exigências da entidade organizadora e promoção interna e externa de atributos que pudessem aferir viabilidade à recepção de um megaevento. Esforços de consolidação de imagem e requalificação urbana foram realizados pelos governos municipal e estadual, durante todo o período de preparação e

\footnotetext{
$4 \quad$ Segundo dados do IPECE (Instituto de Pesquisa e Estratégia Econômica do Ceará) há altos índices de concentração de renda na capital cearense: http://www.ipece.ce.gov.br/apenas-7-da-populacao-defortaleza-concentram-26

Segundo dados do IBGE de 2012, Fortaleza possui o $9^{\circ}$ maior Produto Interno Bruto do país: http://g1.globo.com/ceara/noticia/2012/12/fortaleza-tem-9-maior-pib-do-brasil-e-o-maior-do-nordestediz-ibge.html
} 
realização do evento. Dentro deste contexto, onde se encaixa um bairro apontado como o de mais baixo Índice de Desenvolvimento Humano (IDH) ${ }^{6}$ da Capital? Quais suas perspectivas e possibilidades de participação em um espetáculo de alto padrão e projeção mundial?

São perguntas que pautaram as ações do Conjunto Palmeiras, bairro da periferia de Fortaleza, localizado a aproximadamente três quilômetros da Arena Castelão. É uma comunidade com histórico de mobilização social e uma experiência de economia solidária bem-sucedida. A comunidade buscou, durante todo o período de expectativa e realização da Copa, modos de fazer parte dessa experiência, de incluir-se.

O contexto de realização de um megaevento apresenta-se hoje como uma estratégia de marketing de lugares (KOTLER et al, 2006), garantindo visibilidade para a cidade. A imagem do lugar precisa ser trabalhada, mas já encontra destaque por tornar-se sede: "no contexto de modernização tecnológica e de infraestrutura, a cidade, em processo de reestruturação econômica é tornada produto, uma marca ela mesma" (SÁNCHEZ, 2010, p.68).

Dentro dessa lógica, colocam-se estratégias de invenção destas novas identidades, agora não mais corporativas, mas com intenções de serem vistas e reconhecidas pelo mercado de lugares, de adentrar o imaginário que "não é apenas a representação simbólica do que ocorre, mas também um lugar de elaboração de insatisfações, desejos e busca de comunicação com os outros" (GARCÍA CANCLINI, 2008, p.21). Trata-se de um lugar que pretende construir-se positivamente e atrair os desejos de consumo de torcedoresturistas e, em segundo plano, do próprio morador. O Palmeiras parece enxergar esta articulação e passa, então, a procurar espaço para ser parte da imagem desta cidade-marca:

Desde 2010 o Conjunto Palmeiras se prepara para a Copa das Confederações 2013 e Copa do Mundo 2014. O objetivo é trazer o turista para conhecer o Grande Jangurussu, dando visibilidade, ajudando na geração de renda e no desenvolvimento socioeconômico da região, numa perspectiva do turismo comunitário e da economia solidária (texto do cartaz Banco Palmas na Copa das Confederações).

\footnotetext{
6 Nota divulgada pelo Conjunto Palmeiras no site do Instituto Palmas por ocasião da divulgação de um relatório municipal que classifica o bairro com o pior IDH da cidade: http://www.institutobancopalmas.org/conjunto-palmeiras-x-idh/
} 
Indo na contramão da rejeição encontrada em movimentos populares e comunidades que se organizaram para firmar oposição à realização da $\mathrm{Copa}^{7}$, o Conjunto Palmeiras assume um discurso de integração à lógica do megaevento no que concerne às implicações da cidade transformada em ativo de negociação, Fortaleza tornou-se a cidade-sede da alegria e a periferia poderia ser parte disto, com os esforços de integração que envolveu a realização de eventos, o planejamento de tours pelo bairro e a presença no aeroporto com a exposição da história e da produção da comunidade. Durante o planejamento desta programação surgiu o projeto de criação de uma marca para o bairro, que compusesse o projeto, "\#Por uma Copa democrática: a periferia entra em campo"8 e, pós-evento, permanecesse como a representação do bairro. Uma sugestão que partiu das lideranças e envolveu a participação dos jovens da comunidade e parceria com a Universidade Federal do Ceará.

O presente artigo trata do processo de elaboração desta marca, das motivações e expectativas. "O que leva um bairro como o Palmeiras a buscar a integração por meio de uma marca?" é a pergunta que direciona as reflexões aqui empreendidas, visando analisar que tipo de imaginário este bairro quer construir e de que forma o contexto influencia a busca por dizer quem são como comunidade, fazer-se ver como parte da cidade-sede, não incluída nos guias oficiais, mas em busca de ser parte do roteiro.

\section{A criação do conjunto palmeiras}

O Conjunto Palmeiras foi criado no início dos anos de 1970 em uma área sem nenhuma infraestrutura. Era uma grande fazenda desapropriada pelo então governador Virgílio Távora. Recebeu famílias retiradas de áreas de risco, expulsas pela especulação imobiliária e trabalhadores rurais refugiados da seca. O cenário encontrado há cerca de 20 quilômetros do centro da cidade por dezenas de famílias é descrito pelo Sr. Augusto:

7 Comitê popular da copa: https://raquelrolnik.files.wordpress.com/2011/07/cartilha-sobre-a-copafortaleza.pdf

$8 \quad$ A campanha realizada pelos organizadores do Instituto Palmas, braço social do Banco Palmas, para participar da Copa das Confederações e da Copa do Mundo. Ver site: https://www.facebook.com/BancoPalmas/photos/a.10151339970437626.491148.181268502625/1015240 $\underline{6041087626 / \text { type }=3 \& \text { theater e http://www.institutobancopalmas.org/periferiaentraemcampo/ }}$ 
Aqui no Palmeiras não tinha água, não tinha energia, não tinha transporte, tinha um ônibus só da Viação Cruzeiro. Esse ônibus dava uma viagem de manhã e outra de tarde. Então muita gente perdeu o emprego porque não tinha transporte. Mesmo assim, a gente ficou trabalhando assim, com muita dificuldade... A mão de obra do Palmeiras era uma mão de obra muito barata, hoje ainda continua, mas na época era muito mais difícil ${ }^{9}$.

Por meio de mutirão e com o apoio das Comunidades Eclesiais de Base (CEBs), os moradores foram se organizando e construindo as primeiras casas, escolas, creches e ruas do conjunto. A Associação dos Moradores do Conjunto Palmeiras (ASMOCONP) foi a forma de organização encontrada para conseguir dos governos estadual e municipal luz, água e transporte. Em um desses embates relatados por Augusto, eles conseguiram a luz:

\begin{abstract}
Mas nós, na luta da luz, nós trouxemos o presidente da Coelce aqui 9 horas da noite, levamos lá no Palmeiras 2, no Palmeiras 1 tem sapato de rico enterrado até hoje, tem sapato de rico lá e nós fizemos a propósito. Fizemos a propósito, levamos eles pra lá e caíram em um buraco, mas aí nós botamos a propósito pra eles caírem, pra eles voltarem descalços mesmo. Realmente, nem precisava levar eles pra lá, tudo no escuro era preciso eles caírem dentro do buraco (risos) pra gente ter a nossa energia. E eles colocaram energia no Palmeiras.
\end{abstract}

A diferença entre a casa e a rua mostrada por Roberto DaMatta (1986) não existia na chegada dos primeiros moradores do Palmeiras. As barracas de lonas e os grandes galpões, construídos pelo governo em meio ao terreno da antiga fazenda, abrigavam até seis famílias, como relata o Sr. Augusto, “...eu imaginava, e hoje eu ainda imagino, como é que ficavam aquelas seis famílias num galpão na hora de dormir sem ter uma mínima estrutura". As pessoas se uniram e construíram o bairro. A Dona Irismar, a primeira parteira, se comove ao descrever a precariedade do lugar e a união das mulheres para terraplanar o chão e trazer água em latas durante as madrugadas:

Era só o terreno. Isso aqui era dessa altura de barreira, de buraco, nós, nós representante de quadra, nós mulher, era que de noite nós se juntava tudim, cada uma com uma enxada derribamo pra igualar pra ficar... pra ficar assim como tá. Foi... nós trabalhemo muito... Ói, nós num durmia não, porque além de fazer esse trabalho e a gente ia lutar por água. Que só tinha... Construiro um chafariz bem aqui de lado assim... A gente passava té de... Até de madrugada butando água. ${ }^{10}$

9 Entrevista com Augusto Barros Filho em 22.05.2014 pelo Grupo de pesquisa de Imagem, Consumo e Experiência Urbana (GICEU).

10 Entrevista realizada com Dona Aurismar 23.pelo Grupo de pesquisa de Imagem, Consumo e Experiência Urbana (GICEU). 


\section{míDiA

Os moradores do Palmeiras estabeleceram a união, a solidariedade e a luta como forma de conseguir um lugar para viver com dignidade. Com a organização dos primeiros moradores funda-se a ASMOCONP que posteriormente cria o Banco Palmas ${ }^{11}$, um banco comunitário com um projeto de economia solidária que procura promover $\mathrm{o}$ desenvolvimento econômico do lugar. O ex-coordenador do banco e articulador desse projeto, João Joaquim Melo Neto, explica que “...quando criamos o Banco Palmas, tínhamos apenas R\$ 2.000 e cinco pessoas da comunidade acreditando nesse sonho." $\mathrm{O}$ banco movimenta a economia do bairro financiando e investindo em microempresas. Logo na entrada do bairro, percebe-se a presença do projeto: "Bem-Vindos ao Conjunto Palmeiras, o bairro da economia solidária".

O nome das ruas é outra surpresa para quem visita o Palmeiras - Rua do Pensamento, Rua do Mulambo, Rua da Alegria, Rua Coqueiro. Algumas são homenagens a artistas, poetas, escritores ou cantores, como: Ângela Diniz, Oscarito, Raquel de Queiroz ou Álvaro Dias e do líder seringueiro, sindicalista e ativista ambiental brasileiro Chico Mendes. Os santos da igreja católica também se encontram nas ruas, travessas e nos becos do Conjunto Palmeiras.

\section{Periferia entra em campo}

O Instituto Palmas, o "braço" dos projetos sociais do Banco Palmas, planejou a participação do bairro na Copa do Mundo de Futebol, sob o mote da campanha "Periferia entra em campo". A estratégia era incluir o bairro no roteiro turístico de Fortaleza durante a Copa do Mundo, propiciando ao visitante uma atividade turística diferente, conhecida no Rio de Janeiro como "favela tour". Essa atividade, uma vez consolidada, serviria para dar visibilidade à comunidade. Os representantes de movimentos sociais que atuam no local acreditavam que essa inclusão ajudaria a consolidar a imagem do Conjunto Palmeiras como um lugar de "extrema riqueza" ${ }^{12 "}$.

11 O Banco Palmas foi fundado em 1997, o primeiro banco comunitário do Brasil. A moeda emitida por ele, o Palma, serve de incentivo para que os ganhos e investimentos financeiros permaneçam na comunidade.

12 A expressão foi atribuída por Joaquim Melo, idealizador do Banco Palmas, ao bairro ao associar a riqueza à cultura, a criativa e a solidária se contrapondo a manchete do Jornal O Povo extrema pobreza. 
Percebe-se, contudo, que lugares economicamente e geograficamente marginalizados são apresentados frequentemente pela mídia como perigosos. O famoso "mito da marginalidade" (Perlman, 1976) é a expressão de uma guerra de classes em curso no Brasil urbano. Em 2014, o Instituto Brasileiro de Geografia e Estatística (IBGE) divulgou os dados sobre as características sociais e econômicas de Fortaleza, vulgarmente o ranking da pobreza. Em 20 de fevereiro de 2014, o principal jornal local, O Povo, anunciou: "Conjunto Palmeiras é o bairro de Fortaleza com pior desenvolvimento". Essa notícia afetou a autoestima não só dos moradores, mas também de organizações locais, tais como o Banco Palmas.

Nesse contexto, a campanha "Periferia entra em campo" pode ser entendida como uma continuação dos esforços do Banco Palmas em criar e divulgar uma resposta para enfrentar a mensagem dominante de que a periferia é um lugar de pobreza e violência. Contudo, a Copa do Mundo em Fortaleza foi, mais uma vez, uma iniciativa que lembrou aos seus habitantes mais pobres que eles seriam novamente excluídos. A pesquisa de Robert Alvarez (2016) mostra que a Copa do Mundo foi mais uma demonstração da distribuição desigual da renda em Fortaleza.

\section{Estratégias dos novos movimentos sociais no brasil}

A Copa do Mundo foi vista pela organização do Instituto Palmas como uma oportunidade para chamar a atenção dos visitantes e dos torcedores para as iniciativas culturais e econômicas do bairro. $\mathrm{O}$ aspecto mais relevante dessa ação foi a inclusão da periferia em um megaevento esportivo como foi possível observar em uma das postagens do mundial de futebol no Facebook:

Estamos convictos de que as Copas podem ser eventos bons, justos e democráticos. A programação que organizamos no aeroporto e na periferia já mobilizou milhares de pessoas e empreendimentos da periferia que fazem negócios, geram renda, divertem, promovem a justiça social. $^{13}$

\footnotetext{
13 Publicada na página do Banco Palmas em 24.06.2013. Ver site: https://www.facebook.com/BancoPalmas/photos/a.351370452625.152367.181268502625/101516254201 72626/?type $=3 \&$ theater.
} 


\section{míDiA

Essa iniciativa faz com que o Conjunto Palmeiras seja um bairro singular de Fortaleza. Enquanto outros bairros protestaram contra a Copa do Mundo (ALVES, 2014), o Banco Palmas deu o seu apoio, aproveitando a oportunidade para fortalecer uma vez mais a sua mensagem. Em 2013 e 2014, houve em Fortaleza, assim como no restante do Brasil, vários protestos contra os gastos com a copa e as exigências estabelecidas pela FIFA. O "Não vai ter Copa" levou às ruas cerca de 150 mil pessoas de diferentes movimentos sociais, que protestaram contra a organização do evento (ALVES, 2014).

Os cientistas sociais que estudam a transformação global dos movimentos sociais (MELUCCI, 1980) e os movimentos sociais no Brasil (HOCHSTETLER, 2000; ALVAREZ, 2009), têm notado uma mudança nas estratégias desses movimentos a fim de atingir seus objetivos. Kathryn Hochstetler (2000) argumenta que os repertórios estratégicos dos movimentos sociais brasileiros mudaram depois de 1985. Os novos repertórios estratégicos incluem networking sem protesto, participação em conselhos governamentais e redes internacionais e ocupação do solo. A essa lista nossa pesquisa adiciona campanhas como a "Periferia Entra em campo", que aproveita a realização de um evento com repercussão internacional para chamar a atenção para uma causa que o movimento defende. Por meio da ação \#PeriferiaEntraEmCampo, o Instituto Palmas procurou dar visibilidade aos projetos de economia solidária e criativa realizados na periferia de Fortaleza.

Embora as imagens sejam constituídas individualmente, há uma imagem pública construída por meio de memórias, eventos e patrimônios que motivam as visitações a determinados lugares. Como exemplo, pode-se citar a "história de luta" do bairro. Essa estratégia já foi utilizada anteriormente por outros movimentos sociais para captar legitimidade na luta pelos direitos dos cidadãos (PERRY, 2012). Apostando nisso, a comunidade do Conjunto Palmeiras decidiu, a partir de uma ação de comunicação, integrar o bairro, normalmente excluído dos projetos de desenvolvimento econômico, ao megaevento. A visibilidade das estratégias de posicionamento estabelecidas pelo grupo 
permitiu que a mídia nacional e internacional ${ }^{14}$ percebesse a presença da periferia na Copa do Mundo em Fortaleza.

O fato de que o Banco Palmas deu início a este projeto contribuiu com a sua visibilidade e popularidade. Krippendorf (2003) lembra que há uma necessidade proeminente na sociedade atual de buscar experiências diferentes do cotidiano. Nessa busca pelo diferente, o Conjunto Palmeiras tentou se colocar como uma "outra opção", o turismo da periferia cearense com a apresentação de uma "cultura local", da história de luta da comunidade, da produção artesanal, dos projetos sociais e da moeda social, motivo de orgulho para os moradores da região.

\section{A marca do lugar}

Quando Jean Baudrillard (2007) enuncia que “(...) o lugar do consumo é a vida quotidiana" (p.25), coloca as dimensões de sua Sociedade de Consumo no centro das relações sociais. $\mathrm{O}$ autor descreve uma ordenação de abundância e desperdício em que os produtos e sua fetichização ocupam posição de desejos e encorajam o simulacro de necessidades. As possibilidades de diferenciação e felicidade que as 'coisas' possam trazer, passam a objetivo máximo dos indivíduos, que já não buscam a identificação coletiva e, sim, a diferenciação pessoal. Ao transferir a centralidade do consumo dos objetos para a busca dos indivíduos, Zygmunt Bauman (2008) aponta que "Identidades são projetos: tarefas a serem empreendidas, realizadas de forma diligente e levadas a cabo até uma finalização infinitamente remota" (p.141-142), tarefas que para o autor tentam

14 http://diariodonordeste.verdesmares.com.br/cadernos/jogada/online/musicos-mirins-do-conjuntopalmeiras-recepcionam-turistas-no-aeroporto-1.1045922

http://diariodonordeste.verdesmares.com.br/cadernos/negocios/produtores-da-periferia-estaraono-aeroporto-1.1034000

http://www.lacoperacha.org.mx/impulsan-economia-solidaria-mundialbrasil.phphttp://www.portal2014.org.br/noticias/5511/TURISMO+DA+COPA+NA+PERIFERIA+DE+F ORTALEZA.html

http://globoesporte.globo.com/ce/videos/v/ronaldo-visitou-o-conjunto-palmeiras-emfortaleza/2372089/ 
realizar-se por intermédio do consumo, por seus símbolos e novidades oferecidas incessantemente pelo mercado.

Os bilhetes para espetáculos, os distintivos e outros símbolos de identidade exibidos em público são todos fornecidos pelo mercado. Esse é o segundo expediente oferecido pela modalidade da vida consumista para aliviar o peso da construção e desconstrução da identidade. Os bens de consumo dificilmente são neutros em relação à identidade, tendem a vir com o selo "identidade incluída" (BAUMAN, 2008, p.143).

Esta quebra de neutralidade do que é consumível dá-se por meio de construções simbólicas de atributos qualificadores associados que agregam potencialidades além dos valores de uso, como: valores de troca, diferenciação, construção e comunicação de identidade. Função materializada na forma de marca, que nomeia e caracteriza o que está disponível e almeja conquistar a atenção e os impulsos de consumo de um público previamente identificado. David Aaker (2007) estabelece que a identidade como um atributo central da construção e consolidação das marcas:

\footnotetext{
A identidade de uma marca proporciona sentido, finalidade e significado a essa marca. Ela é central para a visão estratégica da marca e impulsiona uma das quatro dimensões principais do valor da marca: as associações que compõem o coração o espírito da marca (p.72).
}

A marca acumula em si atributos que compõem uma imagem que, por si, comporta traços identitários por sua simples menção. Coloca-se no mercado como ativo valioso, que precisa manter-se atualizado e em sintonia com o mercado e sua constante renovação. Atualmente, “não se vende mais um produto, mas uma visão, um 'conceito', um estilo de vida associado à marca: daí em diante, a construção da identidade de marca encontra-se no centro do trabalho da comunicação das empresas" (LIPOVETSKY, 2007, p.47). O que vale no mercado são as identidades construídas, as narrativas comunicacionais que reforçam o que os 'produtos' à disposição representam para o mercado.

Para as questões levantadas aqui, estas noções interessam na medida em que não estão circunscritas a produtos e serviços oferecidos por corporações; são noções que, na sociedade de consumidores, efemeridade e constante construção de identidades, mesclam-se a dimensões anteriormente preservadas como o próprio indivíduo e o lugar. 
Vive-se um momento em que os lugares ultrapassam a função de abrigar as atividades de consumo, são moldados para atrair atenção e serem consumidos em si.

São as cidades que passam a ser "vendidas" dentro das políticas do Estado, que, no atual estágio do regime de acumulação capitalista, procura cumprir com uma agenda estratégica de transformações exigidas para a inserção econômica das cidades nos fluxos globais. Nesse contexto, não basta renovar as cidades, é preciso vendê-las e, ao fazê-lo, vende-se a imagem da cidade renovada (SANCHEZ, 2010, p.51).

São estratégias que visam atrelar qualificadores à teia urbana, tornar o espaço reconhecido por atributos pré-existentes ou construídos exclusivamente para atrair, mas impreterivelmente apresentados sob um modelo de comunicação que transforma a cidade em mercadoria e a partir disso precisa de sua marca, sua representação de identidade, que a diferencie parcialmente, afinal, a unicidade precisa dividir espaço com a viabilidade que segue padrões internacionais. Uma cidade-mercadoria é uma cidade-modelo, uma experiência de consumo satisfatória que segue, como qualquer produto, as tendências do mercado global. Um dos modos de inserção das cidades nos fluxos globais faz-se via megaeventos, um contexto que firma padrões e uma data para apresentar o lugar, que ocupa a posição temporária de país/cidade-sede, para o mundo.

Fortaleza transformou-se em cidade-sede da alegria, formulou representações do sol, das praias e de seu povo desde a pré-candidatura para concorrer à posição de sede. Sob a justificativa do legado, investimentos foram feitos na concretização do padrão FIFA e a inclusão dos habitantes também ficou restrita à padronização com iniciativas como a FIFA FAN FEST. À periferia, ficaram ações fragmentadas, como a distribuição de alguns ingressos para associações de moradores e a transmissão dos jogos em espaços públicos como os Cucas ${ }^{15}$, os bairros periféricos não fizeram parte dos percursos sugeridos aos visitantes ou imprensa, a cidade-sede que se coloca integralmente para o consumo deixou a maior parcela dos bairros da capital cearense relegados à "invisibilidade".

Por ocasião da comemoração dos 40 anos do Conjunto Palmeiras em 2013, o bairro planejou uma agenda de eventos para comemorar junto aos moradores suas conquistas.

15 Projeto de integração de educação integral e inclusiva da Prefeitura Municipal de Fortaleza: https://juventude.fortaleza.ce.gov.br/rede-cuca 
Esse documento tem por título " 40 anos de muito trabalho e organização comunitária de um povo, que não foge à luta e continua na busca por um mundo mais justo e solidário" e que se inicia com a seguinte descrição:

\begin{abstract}
O conjunto Palmeiras é um bairro situado na Periferia de Fortaleza com uma população aproximada de 40.000 habitantes, cuja história se diferencia dos demais pela forte presença dos movimentos sociais e capacidade organizativa (trecho do documento de planejamento da comemoração dos 40 anos do Palmeiras - 2013).
\end{abstract}

Trata-se de uma comunidade que se vê como diferente, percebe-se um senso de orgulho pelo que foi construído pela organização dos moradores sem auxílios governamentais. Percepções traduzidas nas iniciativas visando ser parte do imaginário urbano inseridos no megaevento de forma positiva, como uma possibilidade de visitação, como um bairro viável que é capaz de suscitar atenção em meio à realização de uma Copa do Mundo. O projeto de criação de uma marca para o bairro surge como tentativa de reafirmação de identidade mercadologicamente viável e tratar dos processos de transformação da cidade em mercadoria.

Fernanda Sanchez (2010) chama atenção para a tendência que os projetos de transformação da cidade em modelo de mercado têm de simular a inclusão atuante dos cidadãos: “a participação da população, estimulada por meio da mídia e do conjunto de campanhas de comunicação, é uma participação legitimadora e não transformadora dessas políticas" (SANCHEZ, 2010, p.419). Ou seja, a integração faz-se superficialmente, os cidadãos "donos do espaço" acompanham a mercadorização de fragmentos de sua identidade urbana serem mercantilizados com uma ilusão de participação. No caso do Conjunto Palmeiras, vê-se uma organização que resiste ao papel de paisagem invisível, partem de uma iniciativa de mercado para fazer ver sua atuação social e suas conquistas.

A cidade colocada à disposição como sede evidencia que, “(...) no âmbito urbano, a redução da cidade a espetáculo se associa ao predomínio do marketing e à captação de investimentos sobre o sentido social dos bens materiais e simbólicos" (GARCÍA CANCLINI, 2008, p.19). Inseridos inevitavelmente nesta lógica, as lideranças do Conjunto Palmeiras lançam mão de uma estratégia do Governo e das entidades 
organizadoras ao buscar a criação de uma identidade visual capaz de traduzir a história, a identidade e o apelo de consumo, por meio da visitação e do conhecimento dos atributos do bairro.

\section{Criação da marca}

A elaboração da marca para representar o bairro na Copa do Mundo começou a partir de oficinas ministradas por integrantes do Grupo de Pesquisa de Imagem, Consumo e Experiência Urbana (GICEU), certificado pela Universidade Federal do Ceará e CNPq, e do PET (Programa de Educação Tutorial) nas salas de aula e nos laboratórios dos cursos de Publicidade e Propaganda e História para 15 jovens ${ }^{16}$ entre 16 e 20 anos do Conjunto Palmeiras. Eles receberam noções básicas de elementos gráficos, cores e conceitos de branding. Das oficinas, nasceram 09 marcas que foram levadas ao Fórum Econômico do Bairro $^{17}$ que selecionaram 03 para serem votadas pela comunidade em uma urna posta na entrada do Banco Palmas e também no site e na página do Facebook do Instituto Palmas (mantenedora do banco). Uma foi escolhida para ser a marca do Conjunto Palmeiras.

A ideia dos organizadores da campanha "\#A periferia entra em campo: por uma copa democrática" era criar uma marca do bairro para a Copa do Mundo de Futebol. A solução encontrada foi realizar oficinas para contribuir na compreensão do que se tratava uma marca em termos de representação. A partir das oficinas de elaboração de marca realizadas, o objetivo mudou e propuseram uma marca para o bairro que permanecesse depois do megaevento e representasse a história de luta e conquista dos movimentos sociais, artísticos e culturais do bairro. Para este artigo, procurou-se analisar o desejo inicial da criação para participar da Copa do Mundo de Futebol da FIFA de 2014.

As três marcas criadas pelos jovens participantes das oficinas traziam elementos de história e identidade atrelados ao bairro:

16 Foram selecionados 15 jovens participantes de projetos sociais no bairro. A visita às dependências da UFC foi estimulante para eles, pois visitar a UFC era algo muito distante da realidade dos jovens da comunidade.

17 Conselho com representantes de instituições e associações que desenvolvem iniciativas de integração social no bairro. 

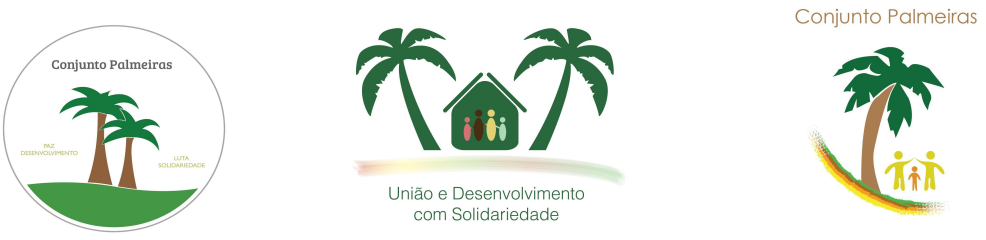

Figura 1: Imagens Selecionadas para votação.

Durante todos os contatos com os participantes da oficina e com as lideranças do bairro, a afirmação que mais se repetia em diferentes formas era como o dia a dia do bairro se diferenciava da imagem retratada nas pesquisas de índices sociais e nas páginas policiais, espaço em que aparece com mais frequência.

As logos produzidas trazem essa preocupação em símbolos e palavras, valores como paz, desenvolvimento, união e solidariedade permearam todo o processo de elaboração e o resultado das oficinas. A votação ocorreu nos canais online do bairro, no site do Banco Palmas e na página do Facebook. Por fim, a selecionada com 52\% dos votos foi a opção 3:

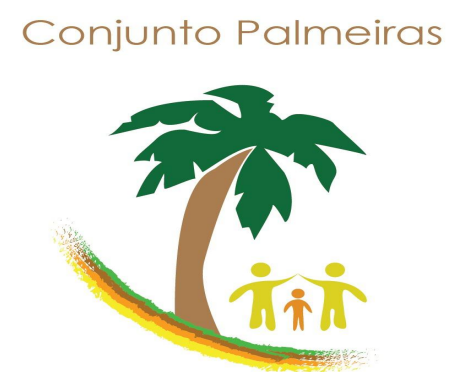

Figura 2: imagem selecionada com $52 \%$ dos votos

A pergunta que nos guia é: o que leva um bairro como o Palmeiras a buscar a integração com o megaevento esportivo por meio de uma marca? Para responder à questão, realizamos entrevistas com um grupo focal dos jovens das oficinas e entrevistas semiestruturadas com os representantes do Fórum Econômico do bairro, responsáveis pela seleção de três das nove marcas apresentadas. 
O objetivo das entrevistas era perceber a importância do megaevento para a comunidade mais pobre e com maior índice de violência de uma das cidades-sede. Após a divulgação da marca premiada, foram realizadas entrevistas com representantes do Fórum Econômico do Conjunto Palmeiras, responsáveis pela primeira seleção das marcas no primeiro momento. Questionou-se qual marca foi escolhida por eles e o porquê da escolha. Observou-se em algumas das marcas criadas nas oficinas a presença frequente das palavras: união, solidariedade, luta e família. Já em termos de representação visual, a palmeira foi a mais citada. As palavras e imagens também serviram de argumento aos entrevistados, como podemos observar no trecho abaixo:

É porque é o início do Palmeiras. Se vocês veem ali, quando vocês vão aqui no carro - vocês vão pra lá, é? - tem um retorno aqui na praça, quando fizer o retorno existem três carnaúbas lá. Aquelas carnaúbas lá são antigas, ninguém não tira. Todo mundo fala, as pessoas antigas, que ali é o símbolo do Palmeiras. Aquelas carnaúbas ali (Entrevistada 1, 45 anos).

É, pela imagem que eu vi, que são duas palmeiras, com uma pessoa, simboliza o que tinha aqui mesmo, muita carnaúba na época. Eu até achei assim, porque num botaram uma carnaúba mesmo, né? Porque hoje em dia nas avenidas eles arrancam árvore e botam carnaúba, palmeira. Tinha muita, viu (Entrevistado 2, 49 anos)?

As palmeiras, a casinha... A casinha principalmente. Quando eu cheguei aqui era tudo piçarra, aquela bem vermelha. Tinha as casinhas de barro, as crianças, as mulheres bem arrepiadas... Então, acho que parece bastante o Palmeiras que eu conheci pequena. A família e tudo (Entrevistada 3, 38 anos).

Percebe-se nas falas dos entrevistados a lembrança da chegada ao bairro, principalmente a presença das palmeiras e a precariedade do local. Para eles, a criação de uma marca pelos jovens com elementos presentes na criação da comunidade é o que eles esperam para representar o que foi construído e conquistado em termos de economia solidária e integração.

A vontade de fazer com que o bairro seja visto em meio a um megaevento de proporções mundiais em que não foram incluídos e muito modestamente convidados não faz com que se perca de vista a identidade do bairro. A ideia não era se adequar à lógica e fazer uma marca semelhante à de Fortaleza na Copa, por exemplo. A iniciativa daria um primeiro passo na mudança de imagem do bairro com uma representação gráfica da história, da identidade e dos valores que costuraram toda a existência do bairro, da 
carnaúba chamada de palmeira às famílias e associações que construíram das casas, a uma das experiências de economia solidária mais bem-sucedida do mundo. Tratou-se de um esforço retratar o que eles conhecem do bairro para quem só vê uma comunidade periférica e distante dos centros de consumo e divulgação turística da capital cearense.

A criação de uma marca representou um exercício importante sob dois aspectos para os jovens do Palmeiras: a tradução da memória de luta do bairro por meio de uma marca e uma reflexão crítica sobre as transformações no bairro em decorrência da Copa do Mundo. Convém lembrar a campanha do bairro para participar do evento: \#Periferia entra em campo: por uma copa democrática. Sobre o primeiro ponto, eles relatam:

A oficina foi muito boa, nunca tínhamos ido a uma universidade e podemos conhecê-la. Foi muito interessante porque fomos nós quem criou a marca do Conjunto Palmeiras, do nosso jeito, pois somos nós quem moramos aqui e sabemos o que se passa no bairro. O que eu e todo o resto quis expressar foi a ideia de união, a força dos moradores para construir o bairro etc. Todos tinham a mesma ideia, só os desenhos foram diferentes. Mas infelizmente meu desenho não salvou, fiquei triste, mas é assim mesmo (entrevistada, 17 anos).

Eu quis passar desenvolvimento, como o Bairro se desenvolveu bastante. Quis mostrar que o Conjunto Palmeiras não é só um lugar violento, como a mídia mostra. A mídia só mostra esse lado. A mídia mostra o lado bom dos bairros que tem dinheiro, como o Meireles, Aldeota. Mas da periferia, só mostra o lado ruim. Porque eles não vêm mostrar e apoiar o trabalho não só do Banco Palmas, mas dos diversos projetos que existem aqui? Agora, se for contar o número de jornais policiais que fazem questão de dizer que o Conjunto Palmeiras é um bairro violento... Nós fizemos aqui uma Caminhada da Paz e entramos em contato com as emissoras para virem cobrir o ato. Eles se comprometeram em vir, mas não apareceram. Porque eles não se interessam em mostrar esse lado do bairro (entrevistada, 18 anos)?

Para eles os bairros pobres de Fortaleza ainda são mostrados pelos veículos de comunicação de maneira negativa apresentando frequentemente a violência como a imagem do lugar. Para Angelo Serpa (2011) ocorrem diferentes processos de apropriação sócio espacial por parte dos meios de comunicação nas cidades contemporâneas: "a existência de dois 'sistemas' que recortam e 'fabricam' lugares de modo diferenciado" (SERPA, 2011, pág. 18).

Sobre a Copa do Mundo de Futebol, os jovens da periferia demonstram descrédito sobre as propostas de transformação na cidade em decorrência do megaevento. Para eles, preponderam os aspectos negativos, principalmente no que se refere à mobilidade. 
Entretanto, sinalizam que o incômodo maior é a exclusão dos pobres do evento, como podemos perceber nas falas:

A iniciativa do Instituto Palmas é muito boa, porque nós da periferia não temos condições de assistir aos jogos no Castelão. Acho isso um absurdo. Eu tenho que pegar uma autorização na prefeitura pra visitar meu tio que mora perto do Castelão. Cadê o direito de ir e vir? Não existe (entrevistada, 16 anos).

No ano passado nós íamos no aeroporto fazer a divulgação do evento que haveria no bairro. A prefeitura deveria disponibilizar ônibus pra trazer os turistas pros eventos do Palmeiras. Não é só na Beira-Mar que vai ter evento da Copa. Se eles põem tanta segurança nos bairros que circundam o Castelão, porque eles não trazem os turistas pra cá? (entrevistada, 16 anos)

Mas acho que eles poderiam trazer essas pessoas (estrangeiros) pra cá, pra mostrar que nos bairros mais humildes também existem pessoas de bem, pessoas que querem fazer algo, que são capazes. (entrevistado, 20 anos)

Essas ações podem ser consideradas espaços de atuação dos moradores no sentido de reforçar sua ação coletiva que visa, entre outros resultados, afastá-los dos estigmas que recaem sobre as áreas periféricas das grandes cidades e que associam a pobreza à criminalidade. Para os habitantes do Conjunto Palmeiras, foi uma ocasião em que puderam sentir orgulho do seu banco e da sua moeda local, apesar da condição de pobreza em que se encontram. Alguns grupos de estrangeiros foram conhecer o bairro, o banco e a moeda social.

\section{Considerações finais}

As representações pensadas pelos jovens para o projeto de marketing de lugar da comunidade dialogam diretamente com as raízes do bairro e, embora criadas por ocasião de um megaevento de renome internacional, preocupam-se mais em reforçar o que o bairro é, as bases sobre as quais foi construído do que adequar-se ao padrão FIFA de qualidade. A marca é parte de um projeto de divulgação, mas que não perde de vista o senso de comunidade construído pelas ações de economia solidária e integração continuamente identificadas com a existência do Palmeiras.

A necessidade da literalidade, tanto no uso das palavras quanto no símbolo que se repete nas três propostas que foram para votação, trazem em si essa necessidade de afirmação interna e externa do que eles julgam que o grande público precisa conhecer. 
Trata-se de um processo de autoafirmação da autoestima da existência em comunidade em relação a tudo que foi construído e à abertura que eles tentam galgar diante das ações dos governos, pouco alinhadas com os anseios e necessidades da comunidade. Quando desafiado a representar-se, o bairro é direto e repetitivo nas fórmulas de se reconhecer e querer ser visto como um local de valores de comunidade elevados, distante da imagem reproduzida pela mídia ao retratar somente os episódios de violência e dos governos, ao enxergar os números de baixo interesse econômico e vulnerabilidade social.

Numa cidade como Fortaleza, permeada por contradições, em que a economia está baseada no comércio e no turismo e os índices de distribuição de renda são muito baixos ao mesmo tempo em que possui o $9^{\circ}$ maior PIB do país, a participação em um evento como esse mostra a determinação de um grupo social de se inserir em uma agenda social. O mais instigante é o uso de estratégias de comunicação e marketing: mesmo que não tenha havido uma sistematização no uso das técnicas, as ações alcançaram os objetivos desejados, ou seja, mostraram a existência de uma periferia que não faz parte dos cartõespostais típicos, tampouco deveria ser mostrada para os turistas que visitaram a cidadesede da alegria, conceito criado pela Prefeitura municipal de Fortaleza para divulgar a cidade na Copa do Mundo de Futebol da FIFA 2014 (BELMINO et al., 2014).

Além disso, a iniciativa rompe com a tradição de enxergar a Copa do Mundo como uma "construção simbólica da unidade nacional" em que se anulam, de certo modo, as diferenças e desigualdades que permeiam a estrutura social (GUEDES, 2002). Com a Copa Mundo, Fortaleza se reinventa, assim, como outras cidades-sede de megaeventos (FORTUNA, 2013). A inciativa do Banco Palmas mostra o lado escondido da cidade, o custo social de uma transformação urbana agressiva e injusta, logo no momento em que a cidade quer vender os seus melhores atributos turísticos: as praias, os prédios confortáveis, a alegria. \#Periferiaentraemcampo não deixa que o establishment mascare as contradições da cidade para completar o processo de branding (FORTUNA, 2013).

\section{Referências}

AAKER. David. Construindo marcas fortes. São Paulo. Bookman. 2007, 344p.

ALVAREZ, Sonia. Beyond NGO-ization? Reflections from Latin America. Development, v. 52, n.2, pp. 175-184, 2009. 
ALVAREZ, Robert. The price of Glory: a socio-economic analysis of the 2014 FIFA World Cup in Fortaleza. Tese de Mestrado, Department of Latin American Studies, University of Arizona, 2016.

ALVES, Pedro. Não vai ter Copa: protestos em Fortaleza já têm 152 mil convidados, a 9 dias do mundial. Disponível em: http://tribunadoceara.uol.com.br/noticias/politica/nao-vai-ter-copaprotestos-em-fortaleza-ja-tem-152-mil-convidados-9-dias-mundial/. Acesso em 18 dezembro 2015.

BAUDRILLARD, Jean. A Sociedade de consumo. $2^{\text {a }}$ Ed. Rio de Janeiro: Elfos; Lisboa: Edições 70, 2007, 213p.

BAUMAN, Zygmunt. Vida para o consumo: a transformação das pessoas em mercadoria. Rio de Janeiro: Jorge Zahar, 2008, 199p.

FREITAS, Silvia Helena Belmino; SILVA, Emylianny Brasil da; CARVALHO, Alissa Cendi Vale de. Cidade- sede da Alegria: A Fortaleza da Copa do Mundo nas Páginas do Jornalismo Local. Revista Eptic, v. 18, n.1, pp. 100-118, 2016.

CANCLINI, Nestor Garcia. Consumidores e cidadãos. $3^{\text {a }}$ ed. Rio de Janeiro: UFRJ, 2008.

DAMATTA, Roberto. O que faz o brasil, Brasil? Rio de Janeiro: Rocco. 1986.126p.

DALTON, George. Primitive Mone. In: DALTON, George (ed.). Tribal and Peasant Economies: Readings in Economic Anthropology. New York: The Natural History Press, 1967.

DAMO, Arlei Sander. O desejo, o direito, o dever: a trama que trouxe a Copa no Brasil. Tema Polêmicos, pp. 41-81, 2012.

FORTUNA, Vania Oliveira. Cidade e Megaeventos. Espetáculo midiático, explosão de sentidos. VI Congresso dos Estudantes de Pós-Graduação em Comunicação. Rio de Janeiro, pp. 1-15, 2006.

FREITAS, Ricardo Ferreira; LINS, Flavio; CARMO DOS ANTOS, Maria Helena. Megaeventos: motores de transformação social. Associação Nacional De Programas em Pós-Graduação em Comunicação. Universidade Nacional do Pará. pp. 1-17, 2006.

GUEDES, Simoni Lahud. O Brasil nas Copas do Mundo: tempo suspenso e história. Reunião Brasileira de Antropologia. Gramado, 2002.

HOLCHESTETLER, Kathryn. Democratizing Pressure from Below? Social Movements in the New Brazilian Democracy. In: KINGSTONE, Peter; POWER, Thimoty (eds.). Democratic Brazil: Actors, Institutions and Processes. Pittsburgh: University of Pittsburgh Press, 2000.

IBGE [Online]. Disponível em: ftp://ftp.ibge.gov.br/Estimativas_de_Populacao/Estimativas_2015/estimativa_dou_2015_20150 915.pdf. Acesso em 11 Junho 2016.

IPCE [Online]. Disponível em: http://www.ipece.ce.gov.br/apenas-7-da-populacao-de-fortalezaconcentram-26. Acesso em 11 Junho 2016.

KOTLER, P.; GERTNER, D.; REIN, I; HAIDER, D. H. Marketing de Lugares: como conquistar crescimento de longo prazo na América Latina e no Caribe. São Paulo: Prentice Hall 2006.

KOTLER, Philip; KELLER, Kevin Lane. Administração de marketing. Trad.: Mônica Rosemberg, Claudio Freire e Brasil Ramos Fernandes. São Paulo: Pearson, 2006. 
KRIPPENDORF, Jost. Sociologia do turismo: para uma nova compreensão do lazer e das imagens. São Paulo: Aleph, 2001.

LIPOVETSKY, Gilles. A felicidade paradoxal: ensaio sobre a sociedade de hiperconsumo. São Paulo: Companhia das Letras, 2007, 402 p.

MELO, Joaquim. Viva a Favela: os pobres assumem seu próprio destino. São Paulo: Ideia e Letras, 2014.

MELUCCI, Alberto. New Social Movements: a Theoretical Approach. Theory and Methods, v. 19, n. 2, pp. 199-226, 1980.

PALEY, Julia. Marketing Democracy: Power and Social Movements in Post-Dictatorship Chile. Berkeley: University of California Press, 1999.

PARRY, Jonathan, BLOCH, Maurice (eds.). Money and the morality of exchange. Cambridge: Cambridge University Press, 1989.

PELRMAN, Janice. The myth of marginality: Urban poverty and politics in Rio de Janeiro. Berkeley: University of California Press, 1976.

PERRY, Kaisha-Khan. Black Women against the Land Grab: The Fight for Racial Justice in Brazil. Minneapolis: University of Minnesota Press, 2014.

RIOS. Kênia Sousa. Campos de Concentração no Ceará: isolamento e poder na seca de 1932. Fortaleza: Museu do Ceará/Secretaria da Cultura do Ceará, 2006,112p.

SÁNCHEZ, Fernanda. A reinvenção das cidades para um mercado mundial. 2. ed. Chapecó, SC: Argos, 2010, 555 p.

SERPA, Angelo. Lugar e Mídia. São Paulo: Contexto: 2011, 184p.

TRIPP, David. Pesquisa-ação: uma introdução metodológica. Revista Educação e Pesquisa. São Paulo, v. 31, n. 3, pp. 443-466, set./dez. 2005. 